\title{
Historia personal de la monja Teresa de Jesús*
}

\author{
Francisco Alonso-Fernández
}

Ensayo

\section{SUMMARY}

This book is classified according to the topic and the method respectively as "mysticism and psychopathology" and as "psychohistory" or "personal history". Nobody knew until the twentieth century that the Saint nun Theresa of Jesus came from a jewish family. She was a little and young girl terrified by hell and the Inquisition and mortified by a serious depressive disorder associated with hysterical comorbidity of psychomotor type.

At he age of 40 , our nun became the Spanish mystic number one: a mysticism of passion illustrated with experiences in form of hallucinated fantasies.

Her Christian existential development was very influenced by these factors: the disparity between her parents, the self-repression of her Hebrew lineage, her cyclothymic temperament and a strong erotic tendency.

Key words: Saint Theresa, psychohistory, mysticism, psychopatology.

\section{RESUMEN}

Este libro se cataloga por su temática en "La vida mística y la psicopatología" y por su enfoque metodológico en "La psicohistoria" o "La historia personal". Nadie supo hasta el siglo XX que la santa monja Teresa de Jesús procedía de una familia judía. Niña y joven, fue víctima del terror sobrenatural e inquisitorial y de un grave trastorno depresivo combinado con comorbilidad histérica de tipo psicomotor.

A los 40 años la monja se convirtió en la representante número uno del misticismo español: un misticismo de pasión ilustrado con fantasías alucinadas.

Su desarrollo existencial cristiano estuvo sometido a la influencia de estos factores: la disparidad entre sus padres, el temperamento ciclotímico, la autorrepresión de su linaje hebreo y una fuerte tendencia erótica.

Palabras clave: Santa Teresa, psicohistoria, misticismo, psicopatología.

\section{LA PORTADA}

La portada del libro representa un gran acierto artístico y simbólico que debo agradecer al equipo editorial. Su conjunto se centra en el único retrato de la monja Teresa de Jesús hecho al natural que se conserva en la actualidad. Fue obra del carmelita descalzo italiano fray Juan de la Miseria, discípulo del famoso pintor español Alonso Sánchez de Coello. Se encontraba la madre Teresa entonces en Sevilla y contaba con 61 años, seis antes de su fallecimiento. No se sintió demasiado entusiasmada con el retrato a juzgar por su irónico reproche: "Dios te perdone, Fray Juan, que ya que me pintaste, me has pintado fea y legañosa".

\section{CATALOGACIÓN DE LA MONOGRAFÍA Y ANTECEDENTES PERSONALES}

Esta monografía dedicada a santa Teresa de Jesús, al decir del maestro de la psicohistoria, don Gregorio Marañón, "la mujer más grande de su época", se ubica según su temática en el área de conocimiento del misticismo y la psicopatología, expresado con más precisión: en el sector de la fenomenología de la vida mística y la psicopatología.

La conciencia mística se caracteriza por organizarse en torno a una actitud mental de reverencia al misterio (mysticon, en griego, significa misterio). Con arreglo al tema del misterio, siempre espiritual desde luego, se establece la gran bipartición de la mística en religiosa y laica, y a su vez el misticismo religioso se subdivide en teísta y deísta. Es obvio que el misticismo de santa Teresa fue el arquetipo español del misticismo teísta, o sea el misticismo sacro consagrado a la imagen de Dios y sobrecargado de pasión hispánica.

En cuanto a su enfoque metodológico, esta monografía pertenece a los dominios de la psicohistoria, entendida como una rama de la historia dedicada al estudio comprensivo del personaje, pero no cómo aparece en la sociedad sino cómo él es en persona y por qué es como es. El foco metodológico de la psicohistoria es, por tanto, la comprensión del personaje mediante el establecimiento de las conexiones de sentido que enhebran la historia de su vida. Con este planteamiento, la denominación que me parece más adecuada para esta

\footnotetext{
Texto leido en la Real Academia Nacional de Medicina de Madrid.

Presentación de la obra que con este título publicó el autor en la Editorial Hoja del Monte, Madrid, 2013,240 págs.

Profesor Emérito de la Universidad Complutense de Madrid; Miembro del Comité Internacional de SALUD MENTAL.

Recibido: 2 de abril de 2013. Aceptado: 24 de julio de 2013
} 
rama de la historia es la de historia personal, término que vengo manejando con preferencia en mis libros.

En ambos territorios, el área del conocimiento del misticismo y la psicopatología y el enfoque metodológico de la historia personal, dispongo de varios antecedentes bibliográficos personales que me complace dejar aquí anotados sucintamente con objeto de acreditar mi interés antiguo por ambas cuestiones.

He aquí mis trabajos en el campo de la fenomenología de la vida mística, citados por orden cronológico:

1. "Estampas de estigmatizados místicos". Anales de la Real Academia Nacional de Medicina, 1984;150:355-373.

2. "La nuit dans la vie et l'oeuvre de Saint Jean de la Croix". Actualités psychiatriques (París), 1988; 3: 21-26.

3. "Estigmas, levitaciones y éxtasis". Temas de Hoy. Madrid, 1983; 306 págs.

4. "Inteligencia, Libertad y Santidad". Dolentium Hominum (Vaticano), 1999; 19, 3: 118-129.

También tengo publicados algunos trabajos en la línea de la psicohistoria o la historia personal:

1. El enigma Goya. La personalidad de Goya y su pintura tenebrosa. Fondo de Cultura Económica. México/Madrid, 1999. 290 págs (2a edición, 2003).

2. Historia personal de los Austrias españoles. Fondo de Cultura Económica. México/Madrid, 2000. 286 págs. ( $3^{a}$ edición 2012).

3. Historia personal de don Santiago Ramón y Cajal. En: Schüller (editor): Santiago Ramón y Cajal. Instituto de España. Madrid, 2007. 25-63.

4. Historia personal abreviada de Santiago Ramón y Cajal. En: Garrido et al. (coordinadores): El legado filosófico español e hispanoamericano del siglo XX. Cátedra. Madrid, 2009. 198-203.

\section{UNAS PINCELADAS SOBRE EL LIBRO}

Esta monografía comprende ocho partes u ocho libros (al decir de los antiguos griegos): una introducción, un índice general, un índice onomástico, una relación bibliográfica y ocho ilustraciones. En total 240 páginas.

Cada parte o libro se compone de un número de capítulos oscilante entre cinco y seis, con un total de cuarenta y dos capítulos y su conjunto se atiene al paradigma existencialista. Voy a ofrecer ahora unas pinceladas de cada parte.

Se abre el libro con "El turbulento entorno religioso de Santa Teresa", donde se describen los distintos tipos religiosos con los que tuvo ocasión de conexionarse la monja Teresa de Jesús, más uno dedicado a la Inquisición española.

Merece la pena subrayar aquí algún dato en torno a la creación de la Inquisición española. Cuando se implantó la llamada Nueva Inquisición Española por bula del papa Sixto IV, en 1478 , llevaban funcionando los tribunales del Santo Oficio, manejados, según los tiempos por los obispos o por el papa, cerca de trescientos años en varios países europeos. La Inquisición española se diferenciaba de la Inquisición medieval en poseer una doble naturaleza funcional, al constituir una institución no sólo religiosa sino asimismo política. Tendremos ocasión de ver más adelante cómo se colocó a santa Teresa con recurrencia en el ojo del huracán inquisitorial. Concluye esta primera parte con un capítulo sobre las brujas, representadas en parte como una invención de los fanáticos religiosos y en parte como la identidad imaginaria inducida sobre ellas mismas por el efecto de las drogas untadas en las mucosas.

La segunda parte, "La familia judeoconversa de Teresa de Ahumada", se inicia con el castigo infligido por incurrir en criptojudaísmo al abuelo de santa Teresa, Juan Sánchez de Toledo, por la Inquisición en Toledo. A raíz de esta humillación pública, la familia se trasladó a Ávila, donde el padre de santa Teresa y sus hermanos iniciaron algunos años después un litigio para protegerse y resarcir su crédito social con la ejecutoria de hidalguía. Este litigio que pasó por diversas alternativas a lo largo de tres años, traumatizó profundamente a la niña Teresita, a la sazón entre las edades de cuatro y siete años, con oleadas de terror al infierno y a la Inquisición.

La profunda disparidad entre el modo de ser de sus padres se reflejó en ella en la construcción de instancias psíquicas antagónicas: de un costado un Yo ideal irónico -lo que ella gustaba de hacer- bajo el influjo de su madre, en brusco contraste con el inflexible super Yo -lo que ella no podía hacer- y el riguroso ideal del Yo -lo que se le permitía hacer-, sendas formaciones transmitidas por su padre. La tensa dialéctica registrada entre ambos frentes psíquicos materno y paterno antagónicos concluye en su tierna adolescencia con la imposición de la imagen paterna sobre la materna, pero no sin dejar marcado el primer paso de su vida hacia la disociación mental. Esta tendencia disociativa se consolidó definitivamente con la puesta en funcionamiento del mecanismo de la autorrepresión psíquica con objeto de excluir del campo de la conciencia su procedencia familiar judía.

La tercera parte, "La infancia y la adolescencia de Teresita", comienza poniendo de relieve cómo nuestra protagonista ya a la entrada de la edad escolar reaccionó al fuerte distrés familiar ocasionado por el litigio judicial sustituyendo los intereses lúdicos por las preocupaciones de la familia. De esta suerte, se estableció en ella una falsa madurez precoz que le hurtó para siempre la condición infantil. Fue entonces, a la edad de seis o siete años, cuando se fugó de casa en busca del martirio religioso y cuando, como si fuera una pequeña adulta, comenzó a sentirse invadida por los sentimientos de culpabilidad y de indefensión, relacionados con su adscripción al linaje familiar judío, vivido al tiempo como un obstáculo para ser la mejor cristiana posible y como un riesgo para caer en la horripilante red del Santo Oficio.

Contra esta insoportable constelación de terror y culpa, la niña, pequeña adulta, se sirvió de una estrategia defensiva desdoblada en una vertiente externa y otra interna: en el 
exterior su recurso defensivo fue el ciego sometimiento al criterio del confesor o del director espiritual, personal seleccionado por ella entre el alto clero o entre los consultores de la Inquisición, mientras que en el mundo interior su defensa consistió en excluir del campo de la conciencia su vinculación familiar judía o judeoconversa, valiéndose del mecanismo de la autorrepresión intrapsíquica, defensa psicológica propia del Yo infantil o el Yo débil.

Desde entonces, Teresa de Ahumada, como ella gustó de llamarse durante largo tiempo, vivía no sólo ajena a la índole de su linaje sino como si no hubiera judeoconversos habitando la península ibérica. Pero el tema reprimido en el inconsciente, al estar sobrecargado de presión emocional, continuó emitiendo señales significativas de su atracción por la cultura judía.

Un problema que no se deja neutralizar del todo por el mecanismo represivo constituye un complejo para la psicología profunda. En el caso de la santa de Ávila se trataba del complejo de judaísmo. Fue tal su hermetismo sobre este tema, que ninguno de sus contemporáneos pudo ni siquiera sospechar que ella procediese de una familia judía o judeoconversa, dato que permaneció oculto hasta mediados del siglo XX.

La tranquilidad conquistada por ella merced al mecanismo de la autorrepresión abonó el alto precio de reforzar su funcionamiento mental disociado o fragmentado, disociación que abrió la puerta a la irrupción de fenómenos histéricos.

La parte cuarta, "La joven monja melancólica", se inicia con el ingreso de la joven Teresa de Ahumada en el convento de La Encarnación. La encendida devoción cristiana de la nueva monja se sintió rápidamente frustrada por el ambiente frívolo y festivo del convento, producto de haber sustituido la rigurosa Regla Primitiva por la cómoda Regla Mitigada. Esta grave frustración activó sus genes ciclotímicos hasta hundirla en un profundo trastorno depresivo, agravado con fuertes dolores fibromiálgicos y complicado con sintomatología motora histérica. En resumen, un cuadro clínico que la mantuvo en estado de invalidez durante casi dos décadas. Un largo espacio oscuro de su vida que en su mayor parte pasó en la cama o en la enfermería.

$\mathrm{Su}$ trastorno depresivo, generado con el concurso del temperamento ciclotímico, se deja catalogar hoy como una depresión bipolar tipo II, o sea como una afección adscrita al espectro bipolar. Por otra parte, su cuadro clínico depresivo era tetradimensional o completo, al abarcar las cuatro dimensiones conocidas como el humor depresivo, la anergia o falta de impulso de acción, la ausencia de comunicación con los demás y la desarmonía de los ritmos del sueño y de la alimentación. El síntoma diana de su trastorno depresivo era el sentimiento de culpa. En distintos pasajes de su Libro de la vida se encuentra una enumeración suficientemente detallada de los síntomas, extendidos a las cuatro dimensiones.

Remito al lector interesado a mi libro: "Las cuatro dimensiones del enfermo depresivo". Instituto de España. Madrid, 2009.
Produce admiración la fina perspicacia de la monja al conexionar los dolores y la fatiga, anticipándose casi cinco siglos a la moderna tesis científica de asociar los dolores fibromiálgicos y la fatiga crónica.

El síndrome depresivo posee una especial tendencia para complicarse con sintomatología histérica en las mujeres jóvenes, lo que ocurrió en la juvenil monja Teresa, facilitado por la disposición histérica o disociativa generada por el antagonismo entre sus padres y consolidada con el manejo de la defensa psíquica autorrepresiva. El revestimiento histérico de su afección melancólica se distribuía entre la incidencia de desmayos recurrentes y la pérdida de capacidad motora, hasta impedirle a veces mantenerse en pie o andar.

La histeria de santa Teresa se atenía, por tanto, en un principio, a una sintomatología de tipo psicomotor $-\mathrm{y}$ años después su misticismo también se ilustró con fantasías disociativas o histéricas. Precisemos, porque el asunto es muy delicado y controvertido: la monja Teresa de Ávila tuvo patología histérica, pero no fue una mujer histérica propiamente, en el sentido de tener una personalidad absorbida por la necesidad de llamar la atención o ganarse la estimación de los otros, entregándose a una conducta de seducción o de inspirar compasión. Queda claro, pues, que la monja Teresa de Jesús no fue una seductora ni una limosnera de estimación.

Esto de decir que tuvo patología histérica pero que no fue una persona histérica, es un juicio muy congruente si se considera que entre la patología histérica y el modo de ser histérico existe escasa afinidad, de modo que la mayor parte de las veces la sintomatología sensoriomotora o psíquica histérica fructifica en el terreno de una personalidad no histérica ni siquiera histriónica.

La parte quinta, "La monja veterana Teresa de Jesús, mística y visionaria", se abre con la transmutación de la monja de enferma depresiva inválida en un modelo de mística teísta, agraciada con fuertes éxtasis visionarios y asiduas vivencias de comunicación con Dios, cuando cumplía los cuarenta años. Ella atribuyó esta especie de "conversión espiritual y curación" a la intercesión de san José con el amparo de Jesús. Semejante metamorfosis personal se produjo a partir de su identificación con una imagen idealizada de Jesús doliente, considerado por ella como su esposo, el hombre-dios.

Sus éxtasis se reflejaban exclusivamente en su interior mediante un desbordamiento de emociones y experiencias alucinadas de temática religiosa, con una actitud corporal confinada en la inmovilidad. Eran transportes extáticos genuinos vividos con recogimiento y austeridad, libres de las características espectaculares externas, en forma de actitudes dramáticas y contorsiones, propias de las secuencias extáticas o seudoextáticas fabricadas por las monjas alumbradas para la contemplación de los demás.

La aguda autodescripción de las experiencias místicas personales ofrecida en sus libros permite identificar a la luz de la fenomenología su espectro común en forma de fantasías desiderativas o intimidatorias alucinadas vividas con 
una evidente convicción de realidad, sobrecargadas de una profunda conmoción emocional y alentadas por la vivencia de unión con Dios. Me siento inclinado, por tanto, a pensar que el mundo místico de santa Teresa era un misticismo auténtico, al estilo emocional español, ilustrado con la presencia masiva de experiencias imaginativas disociadas o histéricas, vividas con un sentido de realidad.

Una realidad alucinada que se distribuía, a tenor de su temple vital, entre la aparición amenazadora de los demonios y la comunicación con Dios sobresaturada de felicidad no sólo en sí misma sino porque entrañaba la disipación de su colección de temores al infierno, a la Inquisición o a sus confesores.

El único hecho milagroso que se autoadjudicó santa Teresa fue el de facilitar la ascensión al cielo del alma de alguna persona querida. No participó en cambio en los fenómenos místicos o seudomísticos más sobresalientes dispersos entre el prodigio, el milagro y el fraude, como el ayuno prolongado, la levitación y los estigmas cutáneos.

La parte sexta, "La superveterana madre Teresa de Jesús reformista y fundadora", recoge cómo a la edad de 48 años la madre Teresa inició una nueva trayectoria biográfica como reformadora cristiana entregada a la fundación de conventos organizados a tenor de la severa Regla Primitiva. Tal entrega a una actividad inusitada se enmarca en un brusco ascenso ciclotímico del tono vital.

El intento de resucitar la austera Regla Primitiva despertó la alarma entre los Carmelitas regidos por la descansada Regla Mitigada. Sobre esta contraposición se produjo el estallido bélico entre los Carmelitas Calzados y los Descalzos. La refriega concluyó con el reconocimiento papal de los Carmelitas Descalzos como una provincia independiente, un clamoroso triunfo de la monja Teresa de Jesús, tramitado en gran parte a través de su relación personal y epistolar con el rey Felipe II.

A lo largo de su vida los confesores -con alguna importante excepción- fueron para ella una pesadilla, que casi superaba el horror inducido por el demonio. En la edad veterana avanzada, a los 60 años, ocurrió algo insólito: la mente de la monja Teresa de Jesús se sintió cautivada por el encuentro con el padre Jerónimo Gracián. Su dimensión erótica, hasta entonces confinada de un modo sublimado o simbólico en la esfera espiritual como "la esposa de Jesús", se globalizó al expandirse no sólo a la biografía, en forma de su fascinación por el padre Gracián, sino como tema recurrente de sus libros y poemas.

Su erotismo literario más elocuente estuvo representado por el amor de pareja, eje de su libro Conceptos del amor de Dios, redactado en 1566 bajo el influjo de El cantar de los cantares, del rey Salomón (siglo X a.C.).

El cariño de la monja por el padre Gracián se plasmaba en expresiones transmitidas por correo como "mi Pablo" o "mi Eliseo", apodos de personajes judíos, o calificándolo como el depósito de su amor o como un ángel. Las ausencias del padre Gracián, motivadas con mayor frecuencia por sus desplazamientos a Sevilla, desataban en ella ráfagas de celos recurrentes proyectados contra la superiora del convento.

$\mathrm{Su}$ repulsa por valorar a las personas con arreglo a su linaje casi como si éste fuera un disfraz, la condujo a reservar una capilla del convento de Toledo para el sepulcro de un hombre rico que no era caballero, en contra de la norma. Aludió entonces a que Dios le había comentado "cuán poco al caso harían delante del juicio de Dios estos linajes". La madre Teresa nunca llegó a asimilar en su intimidad por qué la identidad judeconversa podía ser un obstáculo para devenir la mejor monja cristiana posible, lo que le permitió expresar sin remordimientos su judeofilia cultural.

La parte séptima, "La madre Teresa escritora y poetisa", informa acerca de las actividades literarias de santa Teresa, vertidas en una decena de libros y una colección de treinta poesías. La mayor parte de sus libros los escribió a instancia del confesor de turno, lo cual no fue óbice para que no se le permitiera publicar en vida ni uno sólo. Su estilo literario se regía por la llaneza y la naturalidad. Escribía como hablaba. Su mayor mérito literario fue haber legado a la posteridad su autoanálisis psíquico. Como demostración de su oculta relación empática con la cultura judía, se apilan en sus libros las citas de hechos y personajes básicos de la tradición hebrea. Los más enaltecidos y citados eran David, Moisés y Salomón.

La temática de su poemario comprende versos místicos, hagiográficos, eróticos y festivos o infantiles. Entre los poemas de corte erótico destaca el titulado Yo toda me entregué y dí, organizado en torno a esta estrofa:

"Yo toda me entregué y di,
y de tal suerte he trocado,
que es mi Amado para mí
y yo soy para mi Amado".

Entre sus poco hábiles y comprensivos confesores, a los que en más de una ocasión dijo temer más que al demonio, destacó el padre dominico y consultor de la Inquisición, Domingo Báñez, por su deslealtad y sus innobles mentiras, actitud desenmascarada por vez primera en esta monografía.

Al cerrar la vida de santa Teresa me permito interpretar su identidad como una especie de reencarnación de los cristianos primitivos, llamados a la sazón judeocristianos hasta la predicación de San Pablo abierta a los gentiles. La conciencia teresiana era una síntesis de su fervor sincero cristiano y su encendido entusiasmo por la tradición cultural judía.

Llegamos a la última parte, "Intervención de la Inquisición Española en la vida de la monja Teresa de Jesús". El Santo Oficio se introdujo precozmente en la vida de la monja de Ávila bajo la forma de una sombra de terror familiar que se cernía sobre su infancia y no llegó a abandonarla nunca. Su carácter se modeló bajo el influjo de un abuelo castigado por criptojudío y una familia judeoconversa humillada.

La sombra inquisitorial del terror familiar tomó después una entidad amenazadora personal dirigida contra la 
línea de flotación de la monja, de modo que la acusación se extendía por episodios a sus actividades personales básicas: fue acusada como alumbrada en cuanto mística, como erasmista en cuanto escritora, como insubordinada o rebelde en cuanto fundadora de conventos, como bruja en cuanto maestra de novicias y monjas o como deshonesta en cuanto confidente del padre Gracián.

El acoso inquisitorial alcanzó su mayor agobio en Sevilla en los años postreros de su vida. Fue entonces cuando la monja Teresa de Jesús llegó a sentirse más aterrada y confundida. Su destino fue objeto de incensantes rumores. Entre los frailes se extendió la idea de que acabaría quemada por la Inquisición.

Si la monja Teresa de Jesús se salvó de perecer en la pira, fue debido a su identificación con el potencial agresor en forma de una subordinación total al confesor o director espiritual seleccionado entre el alto clero y los consultores de la Inquisición, estrategia respaldada con un comportamiento religioso inmaculado y la solidez de su personalidad resiliente.

Está muy difundido que a título póstumo se la beatificó, se la canonizó y se la nombró la primera doctora de la Iglesia. Lo que apenas ha circulado es que se le denegó en dos ocasiones el nombramiento de copatrona de España.

\section{BREVE ENSAYO FINAL}

Niña, atormentada por el terror al infierno o a la Inquisición. Adolescente, con un ligero toque de frivolidad mundana. Adulta joven, monja apresada por un grave trastorno depresivo, revestido con sintomatología psicomotora histérica. Veterana, mística teísta paradigmática y escritora de una decena de libros y una serie de poemas. Superveterana, fundadora de conventos a tenor de la Regla Primitiva y creadora de una nueva orden religiosa (fallecimiento a la edad de 67 años).

Las cinco fases mencionadas de la vida de santa Teresa están hilvanadas por una conexión de sentido que se desvela en este libro.

Teresa de Ahumada, como ella gustaba de llamarse en la primera etapa de su vida, fue desde su infancia una resignada víctima inocente a causa de haber nacido en el seno de una familia judeoconversa incrustada en un contexto social cristiano. Sus contemporáneos desconocieron su procedencia judía, dato que no fue de conocimiento público hasta mediados del siglo pasado. Un recurso psíquico defensivo tan efectivo como la represión intrapsíquica la permitió vivir olvidando la índole judaica de su linaje, incluso como si no hubiese habitantes judeoconversos en el solar ibérico.

Aunque se apartó radicalmente de la fe en la religión de Moisés por vivirla al tiempo como un obstáculo para devenir una fervorosa cristiana y como un poderoso motivo para caer en las garras del Santo Oficio, nunca renunció del todo a sentirse hebrea. Exhibió este rasgo identitario en su afinidad electiva por mantener una relación empática con mercaderes judíos y en su atracción complacida por incluir los personajes y los hechos de la cultura bíblica judía en sus escritos. Esta actitud ambivalente hacia la condición familiar etnorreligiosa se define en estas páginas como el "complejo de judaísmo".

Santa Teresa fue también víctima del clima indisciplinado y festivo reinante en el convento de La Encarnación, donde ella profesó de monja y se alojó durante la mayor parte de su vida. La profunda frustración vocacional soportada por la monja Teresa de Jesús en semejante ambiente activó sus genes ciclotímicos para hundirla en un grave y profundo padecimiento depresivo dominado por los dolores fibromiálgicos y combinado con una invalidez motórica histérica que la mantuvo encamada u hospitalizada cerca de dos décadas.

A punto de cumplir los 40 años, la madre Teresa de Jesús dio un espectacular salto vital: el salto de víctima del terror, la frustración y la patología a mística española teísta arquetípica, agraciada con episodios de éxtasis sacros visionarios y vivencias cognitivas que la hacían sentirse en asidua comunicación con Dios. Entró así en la fase más feliz de su vida. Incluso se sintió con fuerzas para ponerse a escribir libros, casi todos a instancia de sus confesores, aunque no la permitieron publicar en vida ni uno solo.

La clave de la historia personal de la monja Teresa de Jesús reside en la metamorfosis de víctima inocente infantojuvenil de la condición judeoconversa familiar y del trastorno melancólico a mística española genuina, autora de diez libros y reformista religiosa que se sentía respaldada por Dios. Su condición de mística española queda acreditada por su conmoción emocional extática que se contrapone al misticismo germano del maestro Eckhart, ensalzado por el desinterés hacia las cosas y la serenidad, término interpretado por Heidegger como Gelassenheit que significa calma o placidez.

No, la cabeza teresiana del misticismo español nunca fue calmosa o plácida aunque sí libre, punto sobre el que volveremos. Su exuberante misticismo contó además con una copiosa ilustración en forma de fantasías sacras alucinadas, experiencias que se analizan en este libro a partir de la autodescripción tan precisa como profunda ofrecida por ella misma.

Desde la edad juvenil se capta en las reacciones de la monja Teresa de Jesús la intervención del temperamento ciclotímico, mediante oscilaciones del tono vital espontáneas o inducidas entre la hiperactividad ilusionada y el retraimiento pesimista. Fue su temperamento ciclotímico el factor personal no sólo responsable de su hundimiento depresivo, como ya hemos visto, sino la base sintónica individual que la condujo a conexionarse con la esfera del erotismo.

Durante largo tiempo el erotismo teresiano se sublimó en la esfera espiritual asumiendo ella el papel de "esposa de Jesús". Fue un acontecimiento insólito la globalización del erotismo en el último tercio de su vida, al expandirse en 
forma de vivencias biográficas y de un amplio repertorio de elementos literarios en prosa y en verso. La avalancha tardía de vivencias eróticas biográficas brotó en ella a partir de su deslumbramiento magnetizado infundido por la relación con el padre Jerónimo Gracián. Entre sus recursos eróticos literarios podemos destacar la pasión amorosa de pareja como el argumento de su obra Concepto del amor de Dios, libro escrito motu proprio a la edad de 51 años bajo la influencia de El cantar de los cantares, de Salomón (siglo X a.C.).

El tribunal de la Santa Fe la enfiló como sospechosa de alumbradismo, erasmismo, deshonestidad o brujería. Si la monja Teresa de Jesús no llegó a ser huésped de una mazmorra inquisitorial -aunque no se descarta su encarcelamiento pasajero en Sevilla- se debió a la alianza de su admirable temple resiliente con la protección proporcionada por su elección de confesor o director espiritual entre el alto clero o los consultores de la Inquisición. Esta especie de "identificación con el perseguidor", o sea con los personajes eclesiales, motivo de pavor desde su infancia, la dispensó un amparo muy efectivo contra males inquisitoriales mayores.

No renuncio a concluir este breve ensayo basado en mi libro, sin consignar que fue tan grande y rotunda la inflexión vital experimentada por la monja Teresa de Jesús cuando entraba en los 40 años, que el término metamorfosis -incluso aunque hablemos con el escritor asimismo judío Stefan Zweig de la "embriaguez de la metamorfosis"- se queda corto y exige la ampliación complementaria con la conquista de la libertad personal que le permitió desde entonces ser dueña de sí y de sus actos. Fue tal vez nuestra monja carmelita descalza la primera mujer española que conquistó por sí misma la libertad interna, configurada con un grave sentido de responsabilidad moral, pasando así de ser una criatura maltratada por la vida a una criatura que construye su vida.

A la luz del microscopio psicohistórico representado por la comprensión psíquica, la imagen de la madre Teresa de Jesús se agiganta como una abanderada de la libertad personal, galardón que no podría arrebatarle ni el mismísimo genio de las letras, don Francisco de Quevedo, quien, en cambio, fue capaz de impedir que se la nombrase a título póstumo copatrona de España acompañando al apóstol Santiago.

Para finalizar, debo confesar a los intransigentes y los fanáticos, sin excluir a los agelastas*, mi testimonio de ser reo del peor pecado del que puede adolecer un autor, al decir de Chesterton: "el imperdonable pecado de no desear ser perdonado".

* La palabra "agelasta" es un neologismo inventado por el escritor francés, vanguardista de la novela picaresca, François Rabelais. Vocablo de origen griego que significa "el que no ríe o carece del sentido del humor".

Artículo sin conflicto de intereses 